\title{
IoT Based Detection of Leakages in Gas Pipes
}

\author{
P. Anitha ${ }^{1}$, K. Saranya ${ }^{2}$ \\ ${ }^{1}$ Assistant Professor, Department of Electronic Science, ${ }^{2}$ Student of MSC Applied Electronics, \\ 1,2PSG College of Arts And Science, Coimbatore
}

\begin{abstract}
How to cite this paper: $\mathrm{P}$. Anitha | K. Saranya "IoT Based Detection of Leakages in Gas Pipes" Published in International Journal of Trend in Scientific Research and Development (ijtsrd), ISSN: 24566470, Volume-3 | Issue-4, June 2019, pp.433-436, URL: https://www.ijtsrd.c om/papers/ijtsrd23 722.pdf

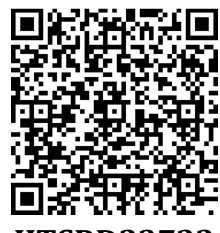

Copyright (C) 2019 by author(s) and International Journal of Trend in Scientific Research and Development Journal. This is an Open Access article distributed under the terms of the Creative Commons

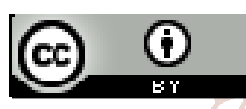
Attribution License (CC BY 4.0) (http://creativecommons.org/licenses/ by/4.0)

On 18, Jan 2019 a pipeline transporting gasoline exploded taking the life of 96 people and a lots of people gets injured. Pipeline monitoring, control, operation and maintenance are very important activities, which have evolved considerably. The detection and behavior of leaks has deserved special attention by different researchers. This paper deals with the detection of leakages in gas pipes and thus reducing the manpower.

\section{PROPOSED PROJECT}

The industrial pipes is widely used nowadays due to the increasing need to transport materials, usually fluids, from one point to another distant one. In many industries this project is used for detecting the leakages of gas pipes which cannot be detected by humans. KROTO comes from a Greek word which denote 'to crack'. The gas pipe has a very high temperature, high pressure and contains toxic gases inside it. The robot which consists of gas sensor that is used to detect the gas leakages. As the robot keeps moving along the metal pipe it keeps monitoring for any gas leakage, the cracks in

the pipe are detected and the condition of the pipe is estimated with the help of Temperature sensor. This data from all the high precision sensors will be displayed in the LCD. The distance of the crack being detected is calculated with the help of Ultrasonic sensor and message is send to the IOT through Wi-Fi module.

\section{ABSTRACT}

In industries leakage of Gas in the pipeline is a major issue nowadays. Leakage is thus reduce loss. Here we propose an inventive robot that clings on to the outer continuouslyalong the metal pipe, if there any presence of leakage the particular position is sensed by ultrasonic sensor and the message is send to the IOT

Keywords: Arduino Uno, MQ 5 sensor, Ultrasonic sensor, Temperature sensor, LCD, I. INTRODUCTION

The Internet of things (IOT) is the network of electronic devices, which are related to embedded systems and also other domains through the internet. Liquids and gases are mostly transported in pipelines like oil, natural gases, biofuels and water. It is necessary to check whether the pipes are good enough without cracks. The cracks may lead to disasters. There is a real life incident which needs to be taken seriously. This project might help to get aware of it. The cruel incident took place in Tlahuelilpan town situated in Mexican state.

\section{III. nt BLOCK DIAGRAM}

The block diagram for IOT based detection on leakages in 56-6470 gas pipe is shown in Fig 1.1

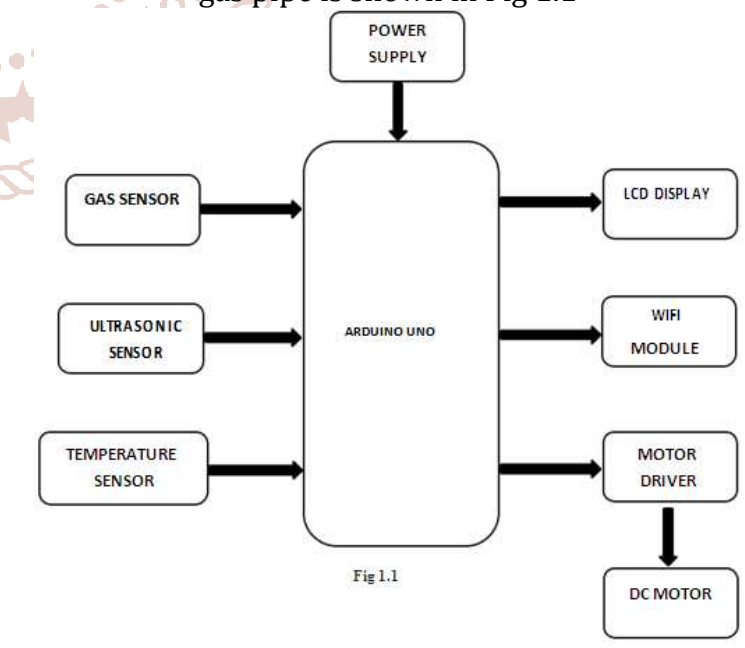

\section{DESCRIPTION}

A. Arduino

Arduino is an open-source easy programming platform which consists of a microcontroller and a part of the software or Integrated Development Environment (IDE) that runs on your PC [1]. The board is designed around an 8-bit Atmel AVR microcontroller or a 32-bit Atmel ARM. Arduino boards are able to read inputs and perform a no of tasks [2]. 
Arduino Uno is a single microcontroller board with 14 digital input/output pins (of which 6 can be used as PWM outputs), 6 analog inputs labeled as $\mathrm{A} 0$ to $\mathrm{A} 5$, a $16 \mathrm{MHz}$ quartz crystal, a USB COM connection, a power jack, an ICSP

Header and a reset button. The fig 1.2 shows the diagram of Arduino Uno. To get started with arduino we have to connect it to the computer with the USB cable or battery or adapter. The various types of arduino boards used are Arduino Uno (R3), Lily Pad Arduino, Red Board, Arduino Mega (R3), Arduino Leonardo.

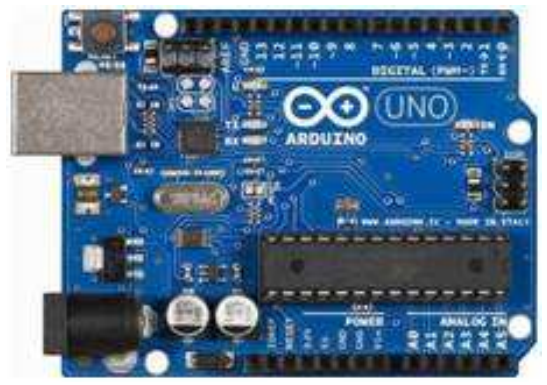

Fig 1.2

\section{B. Gas sensor}

Gas detectors can be used to detect hazardous gas and alert people in danger zone. This type of sensors are used widely in industry shown in fig 1.3 and can be found in locations, such as on oil rigs, to monitor the leakages in pipes [3]. The MQ5 Gas Sensor is a module for detecting the gas leakages. It detects LPG, i-butane, methane, alcohol, Hydrogen, smoke and so on. The sensitivity can be adjusted using potentiometer in the board. The sensor is connected to the analog pin of arduino for reading the inputs and operates on $5 \mathrm{~V}$. The features of the gas sensor is high sensitivity to gas, fast response, stable and long life and simple drive circuit [4].

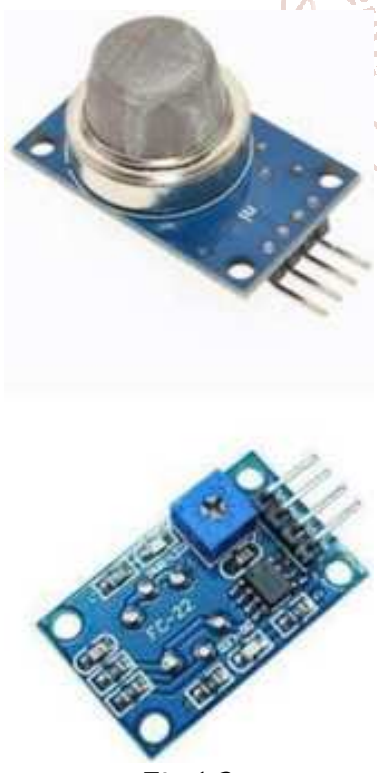

Fig 1.3 nevelons
Distance $L=1 / 2 \times T \times C(1)$

Where $\mathrm{L}$ is the distance, $\mathrm{T}$ is the time between the emission and reception ( $1 / 2$ denotes go and return distance), and $C$ is the sonic speed. The speed of the sound is 343 meters/second (approx. 1125 feet/second). It depends on temperature and humidity. The maximum range for the ultrasonic sensor is about 20 meters (about 70 feet, $3 \mathrm{~mm}$ ) [5]. The Ultrasonic sensor consists of Vcc, Gnd, Trig and Echo pins. The Vcc and Gnd are connected to the arduino board. The Trig pin is the transmitter which sends a high frequency the receiver end for detecting the distance. The time between the emission and reception determines the distance of the object [6].

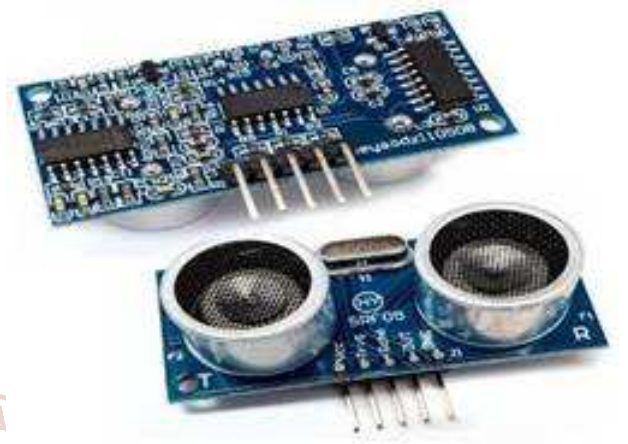

Fig 1.4 signal. The Echo pin is the receiver that collects the signal at

\section{Temperature sensor}

Temperature is a simple thermostatic device which detects physical change and convert into analog or digital output. The contact and non-contact are the two basic types of temperature sensors [7]. The device LM35 is a precision temperature sensor in which the output voltage is proportional to the temperature. The operating range for the sensor is $-55^{\circ} \mathrm{C}$ to $150^{\circ} \mathrm{C}$. It provides accurate reading and has less self-heating. Temperature sensors produce output in Celsius and does not require any external calibration. It consists of Vcc, Gnd, Output pins as shown in fig 1.5 [8].
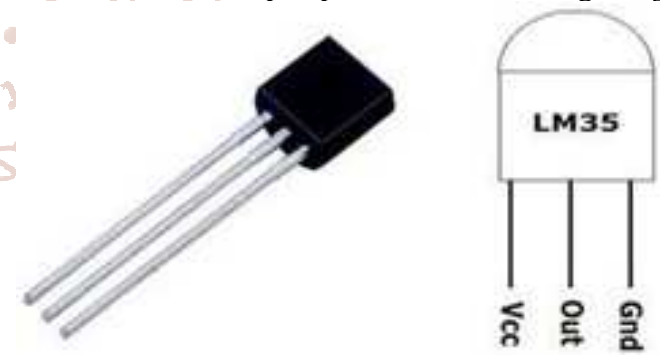

Fig 1.5

\section{E. LCD display}

The liquid crystal display is a basic module used to display alphanumeric characters in most of the embedded projects. It is easy to program, cheap and availability. Here we are using 16x2 LCD display as shown in fig 1.6 which can display 16 characters separately in two rows. It has totally 16 pins in that two pins are used for read/write instruction or data depending on the program. The data will be in ASCII format [9].

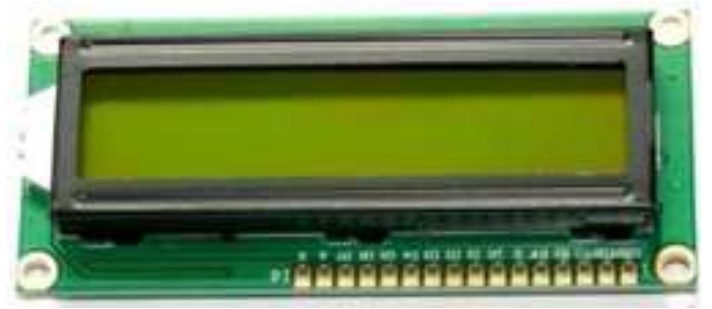

Fig 1.6

\section{Ultrasonic sensor}

Ultrasonic sensors measure distance by using ultrasonic waves. The diagram of ultrasonic sensor is shown in fig 1.4. The head of the sensor emits an ultrasonic wave and consists of separate emitter and receiver but it has some difficulty in processing the correct distance. The ultrasonic sensor reduces the difficulties of radar and most commonly used nowadays. The distance can be calculated as shown in the equation (1). receives the wave reflected back from the target. The radar 


\section{F. Wi-Fi module}

ESP8266 is Wi-Fi enabled system on chip (SOC) module which was developed by Espressif system. It is widely used for development of IoT (Internet of Things) embedded applications. ESP8266 is a 3V Wi-Fi module very popular for its Internet of Things applications as shown in fig (1.7). Its maximum working Voltage is $3.6 \mathrm{~V}$.

ESP8266 module is low cost standalone wireless transceiver that can be used for end-point IoT developments. In order to communicate with the ESP8266 module, microcontroller needs to use set of AT commands. Microcontroller communicates with ESP8266-01 module using UART of specified Baud rate. ESP8266 consists of eight pins. The VCC, chip power down is connected to the $3.3 \mathrm{~V}$ power supply. The GND is connected to the ground. For transmitting the data the RX and TX pin is connected to the $2^{\text {nd }}$ and $3^{\text {rd }}$ pin of the Arduino Uno. It displays the data of gas leakage, distance in $\mathrm{cm}$ and temperature in Celsius.

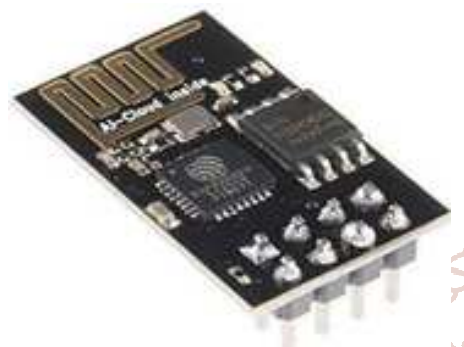

Fig 1.7

\section{G. Motor Driver}

The L293D is a 16 pin motor driver IC which can control two DC motors simultaneously in forward and reverse direction. It consists of 4 inputs, 4 outputs and enable pins for controlling each motor as shown in fig 1 . They are called as current amplifiers because it takes low current from the input and provides a high current at the output which is used to drive the motor. It has two inbuilt H-bridges. All the inputs are in TTL logic [12]. Dc motors are actuators that converts electrical energy into mechanical movement. The dc motor can be switched ON/OFF by switches, MOSFET, relays, transistors etc.

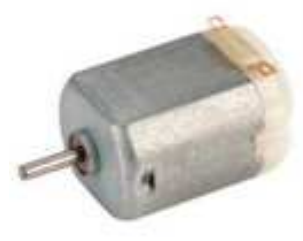

Fig 1.8

\section{SOFTWARE}

In this project we use Arduino integrated development environment platform for programming. It is user friendly to compile the program and upload. It accepts $\mathrm{C}, \mathrm{C}++$ languages. The Arduino is connected to the system using cable.

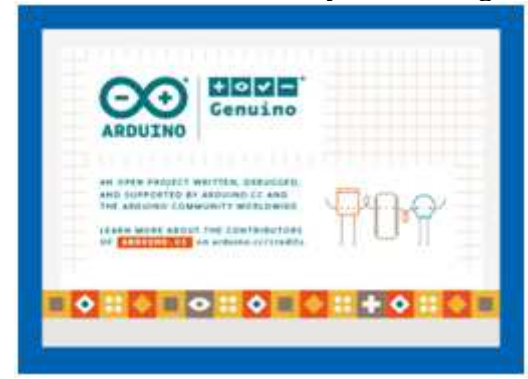

Fig 1.9
Download the Arduino Ide 1.6.12 software as shown in fig 1.9. The programming of the Arduino is divided into two parts namely setup and loop blocks. The setup is used to initialize the input, output ports and devices. The loop block contains the sequence of the program to carry out the particular application. Once the program is verified it is uploaded to the Arduino by connecting it with cable. The serial monitor is used to view the changes in the sensor connected to the Arduino. The Arduino Wi-Fi create a web page for controlling the device with Wi-Fi [13].

\section{WORKING}

The Gas sensor, Temperature sensor and Ultrasonic sensor is connected to the analog or digital pins of the Arduino. All the setup is done in a rover in order to move forward and backward over the pipe. All the sensor output is displayed in digital form in the LCD display. Once the gas value exceeds or limits the threshold value the rover stops at the particular point and the LCD is indicated by "GAS LEAK: YES". At this time the buzzer indicates an alarm for the surrounding people to take safety measures and protection against the leakage. The values of the sensors is also transmitted to the authorized person using the ESP8266 wireless communication protocol. The module is attached with the system and connected to the internet for indication of the message. When the gas level is within the specified range then the LCD is indicated by "GAS LEAK: NO". The distance is specified by centimeter in LCD and temperature sensor in Celsius.

\section{RESULT}

In this project the pipeline is carefully monitored using the rover which is attached to the pipe that reduces the accident due to leakages. It is highly used in industries for detecting harmful gases. This minimizes the man power and safe their life.

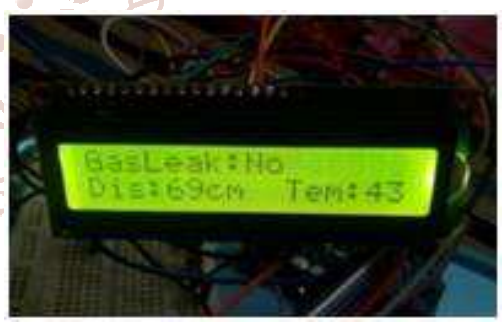

When there is no leakage

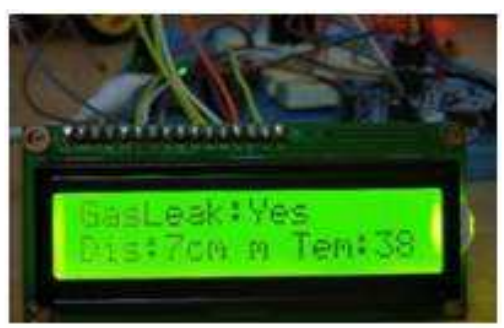

When there is leakage detected

\section{CONCLUSION}

The system designed is very much efficient to use in industries for detecting harmful gases. It reduces the man power by monitoring the level of gas leakage by using sensor and modules. It is highly used in home also for detection of gases in atmospheric level. This is cheaper and easy to program in Arduino by using Arduino IDE software. Compared to the previous related works, the cost of the system prototype is considerably low. It's real time system that sense the leakage of the gas outside the pipe and 
indicate the particular leakage distance using MQ 5 sensor and Ultrasonic sensor. The project provides low cost, long life and high performance in sensing the leakages. It is widely used in industries which transports hazardous gases.

\section{FUTURE SCOPE}

In future the project can be modified to advance technology by connecting sensors around the pipe can detect the leakage even faster and we can add additional sensors for sensing various gases at the atmospheric level. It can be controlled by voice recognition to detect and respond to leakages. Here the distance is calculated by Ultrasonic sensor but in future it can be modified to other type which can calculate even more long distances.

\section{REFERENCES}

[1] https://www.arduino.cc/

[2] Michael McRoberts, "Beginning Arduino", $2^{\text {nd }}$ edition.

[3] F. Rettig, R. Moos, “Semiconductor gas sensors”, (2013).
[4] Huawei electronics Co., ltd, "MQ 5 gas sensor Datasheet".

[5] https://www.keyence.com/ss/products/sensor/senso rbasics/ultrasonic/info/

[6] Elijah J. Morgan, "HC-SR04 Ultrasonic sensor”, (2014) edition.

[7] https://www.electronics tutorials.ws/io/io_3.html

[8] Texas instruments, "LM35 precision centigrade temperature sensors”, (August 1999).

[9] https://electronicsforu.com/resources/ learnelectronics $/ 16 \times 2$-lcd-pinout-diagram.

[10] Spark fun Electronics [US]-Products.

[11] https://en.wikipedia.org/wiki/NodeMCU.

[12] https://www.engineersgarage.com/ electroniccomponents/1293d-motor-driver-ic

[13] BrianW. Evans, "Arduino Programming notebook", 1st edition (August 2007)

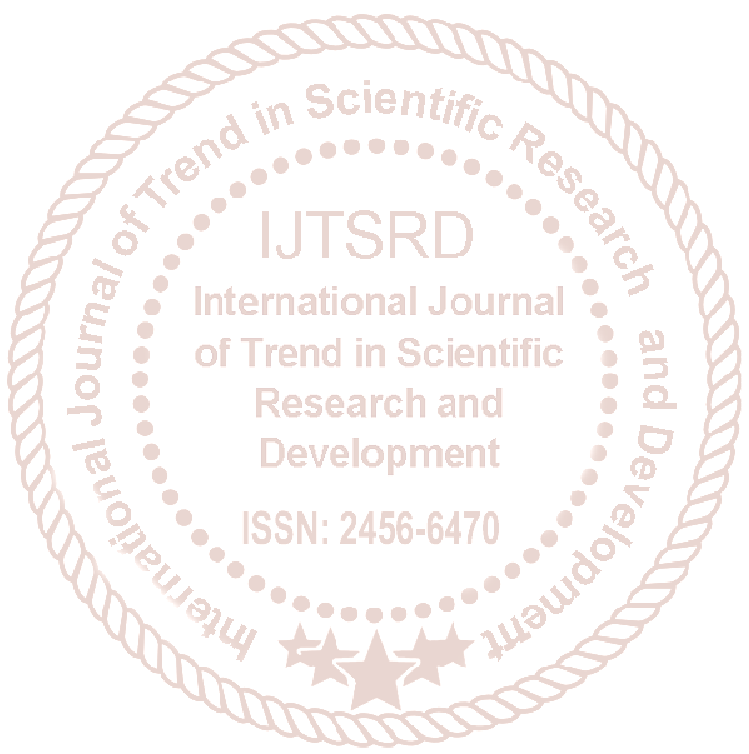

